\title{
Anomalous Innervation of the Median Nerve in the Arm in the Absence of the Musculocutaneous Nerve
}

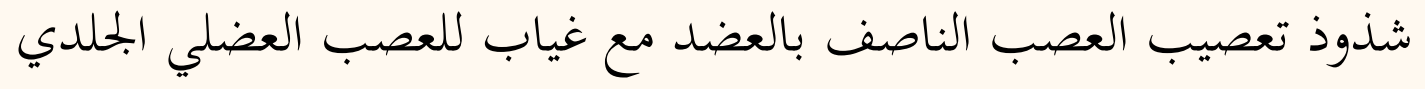

خورشيد رازا، سيما سينق، نيرجا راني، راقف ميصرا، كاماكشي ميهتا، صارجو كالر

ABSTRACT: The brachial plexus innervates the upper extremities. While variations in the formation of the brachial plexus and its terminal branches are quite common, it is uncommon for the median nerve to innervate the muscles of the arm. During the dissection of an elderly male cadaver at the Department of Anatomy, All India Institute of Medical Sciences, New Delhi, India, in 2016, the coracobrachialis muscle was found to be supplied by a direct branch from the lateral root of the median nerve and the musculocutaneous nerve was absent. The branches of the median nerve supplied the biceps brachii and brachialis muscles and the last branch continued as the lateral cutaneous nerve of the forearm. These variations may present atypically in cases of arm flexor paralysis or sensory loss on the lateral forearm. Knowledge of these variations is important in surgeries and during the administration of regional anaesthesia near the shoulder joint and upper arm.

Keywords: Anatomic Variation; Dissection; Median Nerve; Musculocutaneous Nerve; Case Report; India.

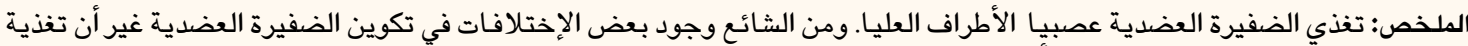

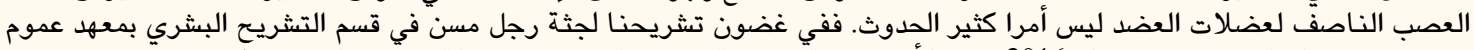

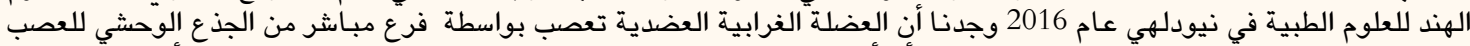

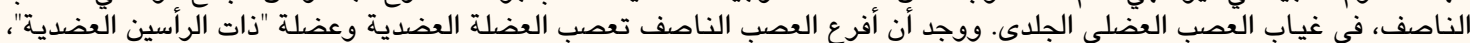

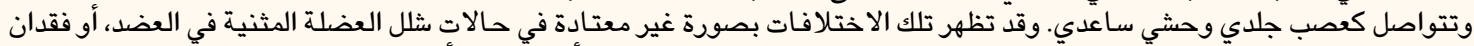

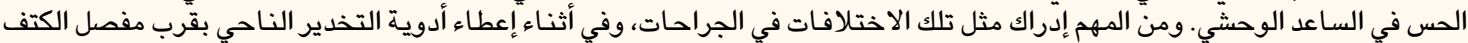
والعضد العلوي. الكلمات المفتاحية: الاختلافات التشريحية؛ التشريح؛ العصب الناصف؛ العصب العضلي الجلدي؛ تقرير حالة؛ الهند.

T HE BRACHIAL PLEXUS INNERVATES THE UPPER extremities and is a complex network of nerves formed by the union of the ventral primary rami of the spinal nerves-from the cervical (C) 5 to $\mathrm{C} 8$ vertebrae and the thoracic (T) 1 vertebra-with a small contribution from the $\mathrm{C} 4$ or T2 vertebrae. ${ }^{1-3}$ Variations in the formation of the brachial plexus and its terminal branches are quite common; however, it is uncommon that the median nerve innervates the muscles of the arm. ${ }^{4}$

\section{Case Report}

An upper limb dissection of an elderly male cadaver was performed during a routine educational dissection at the Department of Anatomy of the All India Institute of Medical Sciences, New Delhi, India, in 2016. During the dissection, the brachial plexus was observed to have a unilateral anomalous branching pattern. All of the usual branches of the medial and posterior cords were present; however, branches from the lateral cord were unusual in the left axilla. The left lateral cord gave rise to a lateral pectoral nerve and, distal to this branch, it continued as the lateral root of the median nerve around the third part of the axillary artery. The musculocutaneous nerve was absent. A branch originated from the lateral root of the median nerve and supplied the coracobrachialis muscle.

The median nerve was formed by the union of the medial and lateral roots from the respective medial and lateral cords of the brachial plexus, anterior to the axillary artery. The branches from the median nerve supplied the flexor muscles of the left arm, except the coracobrachialis muscle, and the last branch continued as the lateral cutaneous nerve of the forearm. The first branch from the left median nerve supplied the two heads of the biceps brachii muscle and another branch supplied the brachialis muscle approximately $3.5 \mathrm{~cm}$ below the first branch. After that, a third branch arose and passed deep to the biceps brachii muscle from 


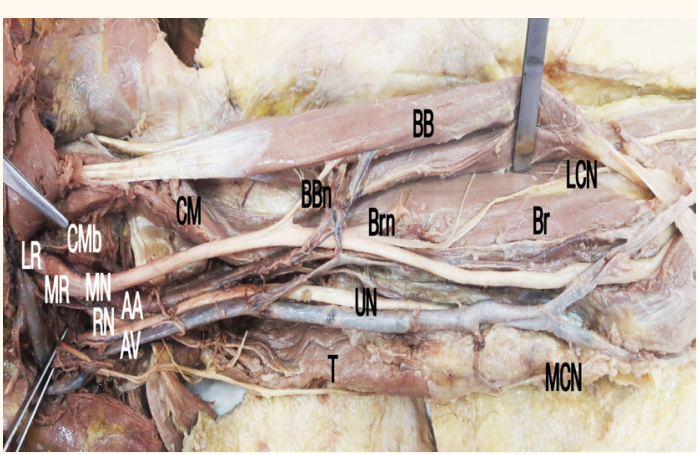

Figure 1: Photograph of the anteromedial aspect of the dissected left axilla and arm of an elderly male cadaver showing branches to the flexor muscles and lateral cutaneous nerve of the forearm from the median nerve. The coracobrachialis muscle was innervated by the branch from the lateral root of the median nerve.

$B B=$ biceps brachii; $L C N=$ lateral cutaneous nerve of the forearm; $B B n=$ nerve into the biceps brachii; $C M=$ coracobrachialis; $B r n=$ nerve into the brachialis; $B r=$ brachialis; $C M b=$ branch to the coracobrachialis; $L R=$ lateral root of the median nerve: $M R=$ medial root of the median nerve; $M N=$ median nerve; $A A=$ axillary artery; $U N=$ ulnar nerve; $R N=$ radial nerve; $A V=$ axillary vein; $T=$ triceps; $M C N=$ medial cutaneous nerve of the forearm

the medial to lateral side, piercing the deep fascia and continuing as the lateral cutaneous nerve of the forearm, superficial to the brachioradialis muscle [Figure 1]. The variation was present unilaterally without any communication between the nerves. No other variations were found in relation to the other vessels and muscles.

\section{Discussion}

Branching pattern variations of the brachial plexus can be explained embryologically. During the fifth gestational week, the fetus develops forelimb muscles due to regional expression of the homeobox $\mathrm{D}$ genes in the mesenchyme of the paraxial mesoderm. ${ }^{5}$ The growth cones of the motor axons arrive at the base of the limb bud to form the brachial plexus and continue into the limb bud. The growth cones are guided by many chemoattractants and chemorepulsants-such as brain-derived nerve growth factor, c-kit ligand, neutrin-1, neutrin-2, slits, semaphorins and ephrins-which work in a highly coordinated manner so that the correct growth cones reach their target before halting and forming synapses. Somatic motor and sensory fibres synapse directly with their target organs. ${ }^{5}$ Any deviation in this phenomenon can lead to variations.

Variations in the formation, branching patterns and communications of the median nerve are well documented [Table 1]. ${ }^{2,6-10}$ In the present case, all of the flexor muscles were innervated by the median nerve proper, except for the coracobrachialis muscle which was innervated directly by a branch from the lateral root of the median nerve, while the lateral cutaneous nerve of the left forearm arose from the median nerve. The variation was present unilaterally without any communication between the nerves. The flexors of the arm and the lateral aspect of the forearm are generally innervated by the musculocutaneous nerve, a branch of the lateral cord, which was absent in the present case. ${ }^{4}$

A previous case report noted a single branch arising from the lateral root of the median nerve, supplying the two head of the biceps brachii. ${ }^{7}$ The coracobrachialis muscle was innervated by a nerve originating from the lateral cord of the brachial plexus while the rest of the flexor muscles were innervated by branches from the median nerve. The lateral cutaneous branch of the forearm also arose from the median nerve, along with a communication between the median and lateral cutaneous nerves of the forearm. ${ }^{7}$ Gümüsburun et al. observed a case wherein the coracobrachialis muscle was innervated by two direct branches from the lateral cord and that the variation was present bilaterally. ${ }^{2}$ Le Minor categorised communications between the median and musculocutaneous nerves; in type V cases, the musculocutaneous nerve is absent and all of the flexor muscles of the arm are innervated by the median nerve. ${ }^{6}$

Nakatani et al. reported three anomalies in which all of the flexor muscles were innervated by branches from the lateral cord and the lateral cutaneous nerve of the forearm arose from the lateral and medial roots of the brachial plexus. ${ }^{8}$ Pacholczak et al. described a case in which the lateral cord pierced and innervated

Table 1: Literature review of anomalous anatomical variations of the median nerve $\mathrm{e}^{2,6-10}$

\begin{tabular}{|c|c|c|}
\hline \multirow{2}{*}{$\begin{array}{l}\text { Author and } \\
\text { year of case } \\
\text { report }\end{array}$} & \multicolumn{2}{|c|}{ Source of innervation } \\
\hline & $\begin{array}{l}\text { Arm flexor } \\
\text { muscles }\end{array}$ & $\begin{array}{c}\text { Coracobrachialis } \\
\text { muscle }\end{array}$ \\
\hline Beheiry $^{7}$ (2004) & $\begin{array}{l}\text { Lateral root of the } \\
\text { median nerve }\end{array}$ & $\begin{array}{l}\text { Branch from the } \\
\text { lateral cord }\end{array}$ \\
\hline $\begin{array}{l}\text { Gümüsburun } \\
\text { et al. }{ }^{2}(2000)\end{array}$ & Median nerve & $\begin{array}{c}\text { Branch from the } \\
\text { lateral cord }\end{array}$ \\
\hline $\begin{array}{l}\text { Le Minor } \\
\text { (1990) }\end{array}$ & Median nerve & Median nerve \\
\hline $\begin{array}{l}\text { Nakatani } \\
\text { et al. }{ }^{8}(1997)\end{array}$ & Median nerve & Median nerve \\
\hline $\begin{array}{l}\text { Pacholczak } \\
\text { et al. }{ }^{9}(2011)\end{array}$ & $\begin{array}{l}\text { Lateral root of the } \\
\text { median nerve }\end{array}$ & Lateral cord \\
\hline $\begin{array}{l}\text { Shinde } \\
\text { et al. }{ }^{10}(2015)\end{array}$ & $\begin{array}{l}\text { Lateral root of the } \\
\text { median nerve }\end{array}$ & $\begin{array}{l}\text { Lateral root of the } \\
\text { median nerve }\end{array}$ \\
\hline $\begin{array}{l}\text { Present case } \\
\text { (2016) }\end{array}$ & Median nerve & $\begin{array}{l}\text { Lateral root of the } \\
\text { median nerve }\end{array}$ \\
\hline
\end{tabular}


the coracobrachialis muscle without any substantial branching and continued as the lateral root of the median nerve; this subsequently led to two branches supplying the rest of the flexor muscles and one branch continuing as the lateral cutaneous nerve of the forearm. ${ }^{9}$ The lateral root joined the medial root of the median nerve at the mid-arm and continued as the median nerve proper. ${ }^{9}$

Variations in lateral cord branching patterns have been associated with other anomalies, such as the splitting of the median nerve into medial and lateral branches wherein the medial branch forms the median nerve proper and the lateral branch innervates the muscles, communication between the median nerve and other nerves or formation of the median nerve in the middle of the arm. ${ }^{6,9-11}$ In addition, it has been reported that the lateral root of the median nerve can bifurcate into two branches, one supplying the coracobrachialis muscle and the other branch functioning as the common trunk supplying the rest of the muscles of the arm and continuing as the lateral cutaneous nerve of the forearm..$^{10}$ In the present case, no such variations were associated with the anomaly.

Variations of the median nerve and its distribution patterns have important clinical and surgical implications, especially when dealing with traumatic injuries of the shoulder, upper arms or axillae., ${ }^{1,4}$ Knowledge of these variations is also important during the administration of regional anaesthesia. In addition, pre-existing median nerve variations may present atypically in cases of paralysis. ${ }^{1,4}$

\section{Conclusion}

This case report describes the dissection of a cadaver in which the left median nerve was found to supply the lateral aspect of the forearm as well as the flexor muscles of the arm, except for the coracobrachialis muscle. This rare variation may result in unexpected clinical presentations in cases of traumatic injuries or paralysis. Knowledge of such variations is therefore of clinical and surgical importance.

\section{References}

1. Ibrahim C, Adnan E, Cem D. Variation between median and musculocutaneous nerves. Internet J Surg 2004; 6:1-3.

2. Gümüsburun E, Adigüzel E. A variation of the brachial plexus characterized by the absence of the musculocutaneous nerve: A case report. Surg Radiol Anat 2000; 22:63-5. doi: 10.1007/ s00276-000-0063-x.

3. Singh S, Rani N, Kaushal P, Kumar H, Sharrif A, Roy TS. Anomalous cutaneous branch of median nerve in arm: A report of anatomical variation with clinical implications. Anat Cell Biol 2014; 47:138-40. doi: 10.5115/acb.2014.47.2.138.

4. Jamuna M, Amudha G. A cadaveric study on the anatomic variations of the musculocutaneous nerve in the infraclavicular part of the brachial plexus. J Clin Diagn Res 2011; 5:1144-7.

5. Schoenwolf GC, Bleyl SB, Brauer PR, Francis-West PH. Larsen's Human Embryology, 4th ed. London, UK: Churchill Livingstone, 2008. Pp. 311-12.

6. Le Minor JM. [A rare variation of the median and musculocutaneous nerves in man]. Arch Anat Histol Embryol 1990; 73:33-42.

7. Beheiry EE. Anatomical variations of the median nerve distribution and communication in the arm. Folia Morphol (Warsz) 2004; 63:313-18.

8. Nakatani T, Mizukami S, Tanaka S. Three cases of the musculocutaneous nerve not perforating the coracobrachialis muscle. Kaibogaku Zasshi 1997; 72:191-4.

9. Pacholczak R, Klimek-Piotrowska W, Walocha JA. Absence of the musculocutaneous nerve associated with a supernumerary head of biceps brachii: A case report. Surg Radiol Anat 2011; 33:551-4. doi: 10.1007/s00276-010-0771-9.

10. Shinde CD, Mane R. Median nerve as a nerve of anterior compartment of arm with its variant formation. Int J Anat Res 2015; 3:1008-10. doi: 10.16965/ijar.2015.146.

11. Budhiraja V, Rastogi R, Asthana AK, Sinha P, Krishna A, Trivedi V. Concurrent variations of median and musculocutaneous nerves and their clinical correlation: A cadaveric study. Ital J Anat Embryol 2011; 116:67-72. doi: 10.13128/IJAE10335 